\title{
POR SERUICIOS MUCHOS E BUENOS QUE ME HA FECHO. LOS CRIADOS DE LAS CASAS NOBILIARIAS CONQUENSES EN LA BAJA EDAD MEDIA
}

\author{
"POR SERUIÇIOS MUCHOS E BUENOS QUE ME HA FECHO". \\ THE SERVANTS OF NOBILITY OF CUENCA IN THE LATE MIDDLE AGES
}

\begin{abstract}
Resumen: Los criados de la nobleza castellana eran servidores que andaban "continuamente" con el señor, incluso algunos se criaban con los hijos del señor. Sus orígenes sociales solían ser humildes, procedentes de otros linajes menores del mismo área geográfica o de las familias de las villas señoriales. A través del paradigmático caso de la nobleza conquense, podemos analizar cómo sus funciones eran principalmente domésticas, administrativas y militares.
\end{abstract}

Palabras clave: Nobleza; Castilla; Cuenca; Política; Criados; Baja Edad Media
JOSÉ IGNACIO ORTEGA CERVIGÓN
Universidad Complutense. Madrid

Abstract: The servants of nobility of Castile were persons who were constant with the lord, and even some they were growing up with the children of the lords. Their social origin used to be humble, proceeding from other minor lineages of same geographical area or of the families of the lordly villas. Across the noble lineages of Cuenca, we can analise how their functions were principally servants, administrative officers and military men.

Keywords: Nobility; Castile; Cuenca; Policy; Servants; Low Middle Ages.

\section{SUMARIO}

1. Introducción: los criados de los linajes nobiliarios castellanos.- 2. Funciones de los criados de las casas nobiliarias conquenses: 2.1. Escuderos, pajes y procuradores: tareas militares, domésticas y jurídicas. 2.2. Vínculos políticos y lazos clientelares. 2.3. El papel de los mayordomos: la gestión de la hacienda señorial.- 3. Episodios de violencia urbana y rural.- 4. Las mandas testamentarias: la vinculación afectiva hacia los criados.- 5. Conclusiones.

\section{INTRODUCCIÓN: LOS CRIADOS DE LOS LINAJES NOBILIARIOS CASTELLANOS}

Durante la Baja Edad Media los criados eran servidores domésticos que andaban "continuamente" con el señor, incluso algunos se criaban con los hijos del señor. Su procedencia social solía ser humilde, pertenecían a otros linajes menores del mismo área geográfica o a las familias de las villas señoriales. Sus funciones eran principalmente domésticas y militares, en especial los escuderos y acostados; también podían realizar tareas administrativas - si eran letrados o secretarios bien preparados- y gubernativas en las 
villas. Recibían un numerario, aparte de los vestidos y los alimentos. Los criados tenían estrechos lazos personales y afectivos con los señores, ya que debían mostrar un alto grado de confianza y fidelidad; así lograban una protección completa del señor, que a veces lograba su exención de pechos y tributos, la concesión de mercedes regias o cargos en los gobiernos locales o algunas dotaciones económicas ${ }^{1}$. El grupo de los criados era una prolongación de la familia, muchos de ellos realizaron su crianza en los propios señoríos, aunque tenían una consideración menor respecto a los hijos y los parientes colaterales directos ${ }^{2}$.

Los nobles han utilizado con frecuencia los lazos clientelares, tanto en su vida cotidiana como para servir sus ambiciones políticas. Algunos especialistas han establecido una clasificación en la relación entre el señor y sus distintos tipos de subordinados: los criados generan un vínculo estructural, mientras que los allegados mantienen una ligazón coyuntural ${ }^{3}$. La solidaridad política y judicial, la protección del uno y la fidelidad del otro que se manifiesta por unos gestos de deferencia, son rasgos de raigambre feudovasallática que también se hallan presentes en el siglo XV.

Entre las características más definitorias del grupo de los criados, la más original y la que le confiere una gran coherencia es el aspecto afectivo. La cohabitación y la crianza con el señor parecen un elemento muy importante, ya que era habitual que algunos jóvenes adolescentes entraran al servicio de un noble o pariente rico y poderoso, con el fin de recibir una educación y ejercer un servicio de paje (que podía durar hasta ocho años) para desarrollar funciones militares o administrativas. En el reino castellano, según consta en algunos testamentos, los criados pajes recibían un salario anual que oscilaba entre 2.500 y $3.000 \mathrm{mrs}$. Según la intermitencia de las prestaciones recibían una quitación, una ración o un acostamiento, si era un servicio ininterrumpido: un continuo -servidor de armas- percibía 20.000 mrs. de quitación y ración, un escudero - menos experimentado en las artes bélicas- $12.000 \mathrm{mrs}$. y un alcalde - que no vivía en común con el señor- podía recibir $5.000 \mathrm{mrs}$. de acostamiento. En ocasiones, los criados se beneficiaban de las exenciones fiscales de la mayoría de impuestos indirectos, según el antiguo privilegio que

${ }^{1}$ I. BECEIRO PITA y R. CóRdOBA DE LA Llave, Parentesco, poder y mentalidad. La nobleza castellana siglos XII-XV, Madrid, 1990, pp. 123-146. En varios testamentos nobiliarios se agradecían servicios a los criados, se hablaba de su cariño, se les beneficiaba con legados y se les encargaba el cuidado de la mujer, los hijos y la hacienda, M. ${ }^{a}$ C. CARLÉ, La sociedad castellana en el siglo XV: los criados, "Cuadernos de Historia de España", LXIX (1987), p. 110. Una visión de conjunto en el trabajo de I. BECEIRO PITA, Criados, oficiales y clientelas señoriales en Castilla (siglos XI-XV), "Cuadernos de Historia de España", LXXV (1998-1999), pp. 59-84.

${ }^{2}$ I. BECEIRO PITA y R. CóRDOBA DE LA LlAVE, ob. cit., pp. 331-337. La aspiración última de los criados era convertirse en cabeza de su propio linaje y señorío, con casa propia y autónoma, como les sucedía a los segundones de los linajes importantes.

${ }^{3}$ M.-C. GERBET, Nobles et clients dans le Royaume de Castille: criados et allegados en Estrémadure dans des années 1500 , en J. L. Castellano Castellano y F. Sánchez-Montes González (coords.), Carlos V. Europeísmo y universalidad. Vol. IV. Población, economía y sociedad (Granada, mayo de 2000), Madrid, Sociedad Estatal para la Conmemoración de los Centenarios de Felipe II y Carlos V, 2001, pp. 337-345. 
tenían los nobles de escusar, y, en caso de exilio del señor, podían obtener las mismas medidas de perdón ${ }^{4}$.

\section{FUNCIONES DE LOS CRIADOS DE LAS CASAS NOBILIARIAS CONQUENSES}

Los linajes conquenses podrían encuadrarse dentro de la etiqueta de "nobleza de servicio", término acuñado para designar a los linajes castellanos que se encumbraron a los primeros niveles de la actuación gubernamental durante el reinado de Enrique III, gracias a la percepción de títulos, rentas y cargos concedidos por la monarquía ${ }^{5}$. Aun considerando que la nobleza conquense tuvo un protagonismo secundario en el devenir de los principales acontecimientos políticos del reino castellano, conviene apuntar en ella una serie de rasgos comunes: acumulación de un patrimonio señorial en la comarca, diversidad en las fuentes de ingresos económicos, estrategias matrimoniales afines y aspiraciones políticas en los marcos urbano y cortesano. En este último aspecto destaca el desempeño de determinados cargos y oficios cortesanos, que eran traspasados en numerosas ocasiones de forma hereditaria a miembros del mismo linaje. Los principales linajes conquenses de época trastámara ${ }^{6}$ fueron los Albornoz, los Hurtado de Mendoza, señores de Cañete, los Carrillo de Albornoz, señores de Torralba y Beteta, los Carrillo de Mendoza, condes de Priego, los Acuña, condes de

${ }^{4}$ Ibidem, pp. 338-342. A pesar de la ruptura de la cohabitación, los vínculos afectivos podían continuar incluso con carácter vitalicio.

${ }^{5}$ Entre la amplísima bibliografía existente sobre el grupo nobiliario en la Castilla bajomedieval, destacamos, entre los más recientes, el monográfico dedicado a El estamento nobiliario. Poder político y económico, "Anuario de Estudios Medievales" 37/2 (2007) y el trabajo de M. "C. QUINTANILla RASO, La nobleza señorial en la Corona de Castilla, Universidad de Granada, 2008.

${ }^{6}$ Algunas consideraciones sobre estos señoríos en los trabajos, entre otros, de S. de Moxó, Los Albornoz. La elevación de un linaje y su expansión dominical en el siglo XIV, en El Cardenal Albornoz y el Colegio de España, vol. I, Zaragoza, 1972, pp. 17-80; M. ${ }^{\text {a }}$ C. QUINTANILLA RASO, El condado de Priego de Cuenca. Un ejemplo de estrategia señorial en la Baja Edad Media castellana, "Historia. Instituciones. Documentos", 19 (1992), pp. 381-402; Marcos y formas de proyección de la nobleza conquense en su entorno urbano y territorial en Congreso Internacional de Historia. El Tratado de Tordesillas y su época, Valladolid, 1995, I, pp. 131-154; Estructuras y relaciones de poder en la tierra de Cuenca a fines de la Edad Media, en La Península Ibérica en la Era de los Descubrimientos (1391-1492). "Actas III Jornadas Hispano-Portuguesas de Historia Medieval", Sevilla, 1997, I, pp. 707-736; Implantación de la nobleza en la tierra de Cuenca, en J. S. García Marchante y A. L. López Villaverde (coords.), Relaciones de poder en Castilla: el ejemplo de Cuenca, Cuenca, Universidad de Castilla-La Mancha, 1997, pp. 103-132, y J. I. ORTEGA CERVIGÓN, La proyección política y señorial de los Hurtado de Mendoza en Cuenca y su tierra durante el siglo XV, en II ${ }^{o s}$ y III ${ }^{o s}$ Premios de Investigación Juan Gịménez de A guilar, Cuenca, 2003, pp. 9-84. Títulos, señoríos y poder: los grandes estados señoriales en la Castilla centro-oriental, en M. ${ }^{a}$ C. Quintanilla Raso (dir.), Títulos, Grandes del reino y grandeza en la sociedad política. Fundamentos en la Castilla medieval, Madrid, Sílex, 2006, pp. 265-307; El arraigo de los linajes portugueses en la Castilla bajomedieval: el caso de los Acuña en el obispado de Cuenca, "Medievalismo", 16 (2006), pp. 73-92; Crónica de un fratricidio. El linaje Carrillo de Albornoz en la tierra de Cuenca durante la baja Edad Media, "Edad Media. Revista de Historia. Homenaje al profesor Julio Valdeón" 10 (2009) en prensa; Nobleza y poder en la tierra de Cuenca: nuevos datos sobre el linaje Albornoz, "Miscelánea Medieval Murciana", XXXIII (2009), en prensa. 
Buendía, y los Cabrera, marqueses de Moya, cuyos titulares desempeñaron distintos oficios cortesanos y disfrutaron de títulos nobiliarios.

\subsection{Escuderos, pajes $\mathbf{y}$ procuradores: tareas militares, domésticas $\mathbf{y}$ jurídicas}

La documentación muestra a los criados de los linajes conquenses en la realización de diversas tareas de confianza. Los escuderos, que sabían servir un caballo con sus armas, no sólo tenían ocupaciones militares. El escudero Diego de Camargo fue alcalde de las sacas y cosas vedadas del obispado de Cuenca, poder otorgado en 1420 para sustituir al lugarteniente Juan Carrillo, que lo ostentaba por el alcalde titular Pedro Carrillo de Toledo ${ }^{7}$; ese mismo año Diego de Camargo juró el cargo de alcalde ordinario de la ciudad y otro escudero de Diego Hurtado, Juan de Torres, aparece como fiador del alcalde García Álvarez de Salas:

E yo [...] le do todo mi poder conplido con todas sus inçidencias, emergençias e conexidades que dello depende, e desde oy dia revoco qualesquier poder o poderes que para lo susodicho yo aya dado a qualesquier persona o personas e quiero que non valan salvo este que agora aquí do e quiero, e mando e defiendo que otro alguno non se llame alcallde de las dichas sacas nin use del dicho ofiçio salvo el dicho Diego de Camargo ${ }^{8}$.

Muchos sirvientes eran alcaides de fortalezas, como Pedro de Priego - también escudero de Diego Hurtado- lo era de Huélamo en $1448^{9}$.

Diego Hurtado decía que sus escuderos "biuen conmigo e lieuan de mí sueldo, e tierra, e acostamiento, e comen continuamente pan en mis manteles" ${ }^{10}$. Antón de Uclés, escudero de Lope Vázquez, figura como testigo en el reconocimiento de un pago y Suero González, escudero de Diego Hurtado, recibió un poder especial a favor de Diego Rodríguez de Salamanca para demandar y recibir de Juan Martínez, clérigo de Valdecolmenas de Suso, cierta deuda ${ }^{11}$. Pedro Carrillo de Huete tenía como escudero a Gómez

${ }^{7}$ Cuenca 21 marzo 1420, A(rchivo) M(unicipal) (de) C(uenca), leg. 185, exp. 5, fol. 23v24r, publ. Å. CHACÓN GÓMEZ-MONEDERO y P. MARTÍNEZ ESCRIBANO (dir. M. Jiménez Monteserín), Actas municipales del ayuntamiento de Cuenca (Años 1417, 1419 y 1420), Cuenca, 1994 [en adelante Actas...], p. 63.

${ }^{8}$ Cuenca, 7 octubre 1420, AMC, leg. 186, exp. 1, fol. 1r (fol. suelto), publ. ibidem, pp. 8485. Diego de Camargo "dio consigo por sus fiadores a Lope de Flores e a Pero Rodriguez Taveira".

${ }^{9}$ Pedro de Priego también figura como testigo en la donación de la villa de Salmerón que hizo Diego Hurtado de Mendoza al condestable Alvaro de Luna; este documento fue firmado "en presencia de Martín Dias y Furtán González, alcalde de la mi villa de Valdeolivas", 7 agosto 1432, R(eal) A(cademia) (de la) H(istoria), Salazar y Castro, M-25, fols. 206r-207v.

${ }^{10}$ Cuenca, 28 octubre 1417, AMC, leg. 185, exp. 2, fol. 5v. Diego Hurtado mostraba así su confianza hacia sus escuderos, acusados de crear alborotos urbanos en Cuenca, con quienes compartía mucho tiempo en sus actividades diarias.

${ }^{11}$ Cuenca, 10 diciembre 1421, F.A. CHACón GómEZ-MONEDERO, M.T. CARRASCO LAZARENO Y M. SALAMANCA LÓPEZ, Libros de Actas Capitulares de la Catedral de Cuenca. II (1418-1422), Cuenca, Seminario de Cultura Lope de Barrientos-Alfonsípolis, 2008 [en adelante Libros de Actas Capitulares...], docs. 930 y 931 p. 334. También aparece en la documentación de este año Alfonso de Monferrat, escudero de García Álvarez de Álbornoz, Cuenca, 17 enero 
Fernández Zamora - que figuraba como veinte caballero entre 1428 y 1429y dos escuderos del linaje Ochoa en 1446, todos vecinos de Huete ${ }^{12}$.

Los procuradores se encargaban de realizar las operaciones de compraventa o acudir a los procesos judiciales que correspondían a sus titulares. Pascual Sánchez, criado de Fernán Gómez de Albornoz, pidió a Alfonso XI la confirmación de una carta de Fernando IV en la que eximía del pago de portazgo a los vecinos de Cuenca salvo en Toledo, Sevilla y Murcia. Vitorio de Iniesta, racionero de la iglesia de Cuenca, era el procurador de Gutierre de Sandoval, que tenía raciones y prestaciones en las iglesias de San Miguel de Cuenca, Monteagudo, Albendea y Salmerón por valor de 450 florines de oro de cuño de Aragón. En 1417 Juan Sánchez de Molina compró unas casas en la plaza de la Picota en nombre de Diego Hurtado de Mendoza, pero no la hizo efectiva en dinero. Martín de Mariana y Juan Losillo, criados de Diego Hurtado de Mendoza en 1503, actuaron como procuradores en el pleito de las villas de Poyatos, Tragacete y Uña contra el juez de términos de Cuenca $^{13}$.

Los procuradores representaban a los señores en pleitos y demandas ante cualquier señor, alcalde, juez ordinario o delegado - eclesiástico o seglar-. Entre sus cometidos estaban la potestad para demandar, defender, responder, negar, conocer, proponer, exhibir, alegar, requerir, protestar y replicar las posibles acusaciones contra la persona o intereses de su señor. También podían solicitar la repetición del pleito, contestar juramentos, responder a testigos, cartas o instrumentos probatorios que la otra parte presentara, contradecir y reprobar en dichos y personas los crímenes y faltas alegados, concluir sentencias, apelar y suplicar, otorgar albalás, etc. ${ }^{14}$. En general, los procuradores exponían las razones que el propio representado daría en el juicio o fuera de él: Álvaro de Huete era el procurador de Lope de Acuña en el pleito que éste mantenía contra la ciudad de Cuenca por los términos de La Puerta, Peralveche, Mantiel y Cerezuela por haberlos "entrado, tomado e ocupado, e les tenía puestos alcaldes e justicia y por haberse llevado los frutos y rentas dellos, que estimaban en cien mil maravedís anuales hasta su restitución" ${ }^{15}$. Pedro de Arriola, procurador de

1421, ibidem, doc. 693, p. 257.

${ }^{12} \mathrm{~J} . \mathrm{M}^{\mathrm{a}}$ SÁNCHEZ BENITO, El poder en una pequeña ciudad castellana: el ejemplo de Huete en el siglo XV, "En la España Medieval", 25 (2002), pp. 192-193.

${ }^{13}$ Cuenca, 20 abril 1346, AMC, leg. 2 exp. 19, publ. A. CHACón GóMEZ-MONEDERO, Colección diplomática del Concejo de Cuenca 1190-1417, Cuenca, 1998 [en adelante

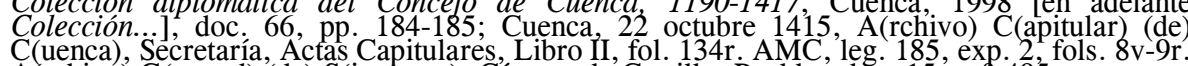
A(rchivo) G(eneral) (de) S(imancas), Cámara de Castilla, Pueblos, leg. 15, n. 495.

${ }^{14}$ Lope Sánchez de Caldas, criado de Elvira López, señora de Las Majadas, recibió de ésta una carta de poder para representarla en una delimitación de términos, Cuenca, 8 mayo 1386 , AMC, leg. 34, exp. 1, publ. Colección..., doc. 121, pp. 286-287. Ruy Ponce de Écija, escribano del Rey, era procurador de Lope Vázquez de Acuña en la segunda década del siglo XV, Cuenca, 12 octubre 1417, AMC, leg. 185, exp. 1, fol. 19r, publ. Actas..., p. 24; tal condición se muestra en otra sesión concejil:" "E luego paresció y presente en el dicho conçejo Ruy Ponçe de Eçija, procurador que se dixo del honrrado caballero Lope Vásques de Acuña”, Cuenca, I noviembre 1417 , AMC, leg. 185, exp. 2, fol. 14r.

${ }^{15}$ Córdoba, 15 abril 1485, AGS, R(egistro) G(eneral) (del) S(ello), fol. 324. 
Lope Vázquez de Acuña en el pleito que éste mantenía contra Antonio de Sotomayor, vecino de Ayllón, le representó ante la petición que aquel presentó ante don Alfonso de Fonseca, arzobispo de Santiago, "presydente de la nuestra audiencia e del nuestro consejo, diciendo que su parte tratava pleito contra el concejo de Olmeda de la Cuesta por un censo de 20 cahíces de pan que le debía, e le debían 1.200 fanegas de pan e más" ${ }^{\prime 16}$.

Otros muchos criados aparecían como testigos en asuntos burocráticos y jurídicos: permutas, donaciones, dotes matrimoniales, pleitos, desposorios o fundaciones de mayorazgos. En la donación del patrimonio de María Albornoz a su primo Álvaro de Luna estaban presentes como testigos su capellán Juan Martínez de Salmerón y su mayordomo en Torralba, Juan Martínez de Castillejo ${ }^{17}$. En el trueque de Carcelén y Montealegre por San Pedro de Palmiches, Juan de la Torre y otra persona firmaron como escuderos de Diego Hurtado de Mendoza ${ }^{18}$. El secretario Alfonso Enríquez fue testigo de la dote que Juan Hurtado de Mendoza ofreció a su hija legítima María Manrique en su enlace con Pedro de Barrientos y Pedro de Mendoza, criado de Juan Hurtado de Mendoza, fue especialmente llamado para la dote de su nieta María de Mendoza ${ }^{19}$. Rodrigo de Rabanal era criado de Juan Hurtado de Mendoza en la disputa que éste mantuvo con su hijo Honorato de Mendoza y su mujer Francisca de Silva; uno de los dos jueces involucrados en esta sentencia era Pedro de Priego, mayordomo de Juan Hurtado de Mendoza ${ }^{20}$. Alfonso Enrique de Valladolid, que había sido secretario de Juan Hurtado de Mendoza y Honorato de Mendoza, fue testigo de la dispensación de parentesco entre dos hijos de Diego Hurtado de Mendoza e Isabel de Cabrera y dos hijas de los señores de Torralba, por ser primos hermanos en tercer grado $^{21}$. En el mayorazgo de La Frontera y Beamud estuvieron presentes Tomás de la Muela, Pedro Marín y García Garcés, criados de Juan Hurtado de Mendoza 22 .

Otras actividades jurídicas en las que figuraban como testigos criados de la nobleza conquense fueron los traspasos de oficios, los traspasos económicos, cartas de confederación entre nobles, pleito-homenajes o traslados de documentos. Varios hombres de Lope Vázquez de Ácuña - Gonzalo Yáñez, Diego Ochoa, Juan de Velasco y García de la Torrefiguraban como testigos en la cesión de una alcaldía a García Álvarez de Salas, Cañamares. Los escuderos de Gómez Carrillo -Pedro González de

\footnotetext{
${ }^{16}$ Valladolid, 20 mayo 1486, AGS, RGS, fol. 154.

${ }^{17}$ Torralba, 6 marzo 1439, publ. J.M. CALDERÓn ORTEGA, Álvaro de Luna (1419-1453). Colección diplomática, Madrid, 1999, doc. 56, p. 185.

${ }^{18} 8$ noviembre 1431, RAH, Salazar y Castro, M-9, fols. 303r-304r.

${ }^{19} 9$ enero 1470, RAH, Salazar y Castro, M-71, fols. 26r-28v y 29 octubre 1498, RAH, Salazar y Castro, M-1, fols. $109 \mathrm{v}-110 \mathrm{r}$.

${ }^{20} 5$ diciembre 1485, RAH, Salazar y Castro, M-9, fols. 38-39v.

${ }^{21} 19$ agosto 1522, RAH, Salazar y Castro, M-10, fols. 207-215v.

${ }^{22} 19$ febrero 1487, RAH, Salazar y Castro, M-10, fols. 318-320v. García Garcés también estuvo presente como testigo en la capitulación de Francisce Hurtado de Mendoza, deán de Cuenca, que renunció en 1496 sus posibles derechos sucesorios en la casa de Cañete à favor de su sobrino Diego Hurtado de Mendoza, AGS, RGS, 21 abril 1497, fol. 8.
} 
Piedrahita, Juan de Torrepineda y Gómez de Córdoba - ejercieron de testigos en el nombramiento de Lope Vázquez de Acuña como alcalde entregador de las mestas y las cañadas. Fueron "testigos que fueron presentes, para esto llamados e rogados", del traspaso del oficio de montero mayor por parte de Diego Hurtado de Mendoza a su hijo Juan Hurtado de Mendoza, "Juan Montero, García de Blanca y Alfón de Priego, escuderos o criados del dicho Diego Furtado. Alfón Gonsáles de Andujar” era escribano público de Cañete, "a la merçed de mi señor Diego Furtado" ${ }^{23}$. Alfonso Enrique de Valladolid y Pedro de Mendoza aparecieron como testigos de la renuncia que hizo Juan Hurtado de Mendoza en su mujer de $7.000 \mathrm{mrs}$. de juro, situados en las alcabalas de Tragacete, Olmeda de la Cuesta y Uña ${ }^{24}$. Rodrigo de Torres, Diego de Vayllo y Enrique, criados del señor Juan Hurtado, figuraban como testigos en el documento que acreditaba la confederación con su sobrino Diego López Pacheco, duque de Escalona y marqués de Villena ${ }^{25}$. Martín de Requena y Alfón de Molina, escuderos de Pedro de Barrientos, dieron fe como testigos del pleito homenaje que éste realizó al rey —en representación simbólica con un regidor de la ciudad- para devolver la fortaleza de Enguídanos a la jurisdicción conquense, y Diego de Paredes, camarero de Diego Hurtado de Mendoza, fue testigo en 1511 del pleito homenaje que éste realizó al príncipe don Carlos y al Rey Católico, en reconocimiento de los derechos sucesorios de la reina doña Juana ${ }^{26}$. Alfonso Enrique, "vesino de la dicha çibdad de Cuenca, en nonbre del muy noble cauallero el señor Juan Furtado de Mendoça, del Consejo del Rey e de la Reyna", solicitó al bachiller Diego Velázquez, teniente de corregidor de Cuenca y Huete, realizar dos traslados de la escritura de mayorazgo otorgado en 1442 por sus padres Diego Hurtado y Teresa de Guzmán ${ }^{27}$.

Algunos testimonios muestran a los criados en sus tareas domésticas, como el despensero o el acemilero. En 1419 Diego Hurtado mandó al sexmo de Chillarón que le diesen tres carneros a su despensero que costaron 150 mrs. y "también se pagó a 4 hombres que los trajeron e para un azemila otros 30 mrs.". Domingo Herráiz, acemilero de Elvira López, señora de Las Majadas, figura como testigo en una carta de poder a favor de su criado Lope Sánchez de Caldas ${ }^{28}$. Los pajes se encargaban de entregar las cartas o de guiar a las personas que visitaban la posada de sus señores. En 1503, estando en Olmeda de la Cuesta, un labrador que llevaba ciertas escrituras para Luis

\footnotetext{
${ }^{23} 8$ octubre 1417, AMC, leg. 185, exp. 1, fol. 19r, publ. Actas..., p. 24; Valladolid 17 septiembre 1417, AMC, leg.'185, exp. 1, foil. s. n., publ. ibídem, p. 25 ;'Cañete, 20 junio 1437, AGS, Escribanía Mayor de Rentas, leg. 682, fol. 341, fol. 2r.

${ }^{24} 13$ febrero 1497, AGS, Mercedes y Privilegios, leg. 168, doc. 39, fol. 2r. 45.

${ }^{25}$ Cuenca, 25 febrero 1477, A(rchivo) H(histórico) N(acional), Nobleza, Frías, leg. 127, n. ${ }^{\circ}$

${ }^{26}$ Cuenca, 11 agosto 1477, AMC, leg. 59, exp. 7, fol. 6v y AGS, Patronato Real, leg. 7, doc. 200 . 7.

${ }^{27}$ Cuenca, 28 febrero 1500, AGS, Cámara de Castilla, Diversos de Castilla, leg. 38, doc.

${ }^{28}$ Cuenca, 8 mayo 1386, AMC, leg. 34 , exp. 1, publ. Colección.... 121, p. 287 y AMC,
leg. 185 , exp. 4 , fol. 3r, publ. Actas..., p. 41.
} 
Hurtado preguntó por la posada de éste a un paje de Diego Hurtado, quien le llevó engañado a la morada de su señor ${ }^{29}$.

En cambio, de otros criados ni siquiera conocemos la ocupación y las referencias documentales no ofrecen más información: Juan Sánchez de Cuenca era criado de Gómez Carrillo y Juan de Antezana servía Diego Hurtado de Mendoza y Juan Hurtado de Mendoza ${ }^{30}$.

\subsection{Vínculos políticos y lazos clientelares}

Bajo los reinados de Juan II y Enrique IV el devenir político de la Corona castellana fue guiado en parte por el sistema de alianzas y solidaridades que se produjeron entre los miembros de la nobleza. En Cuenca también existieron diversas facciones en las altas esferas locales que luchaban por el dominio político de la ciudad. Sus manifestaciones más relevantes tuvieron lugar durante el reinado de Juan II y, más tardíamente, a comienzos del siglo $\mathrm{XVI}^{31}$.

Dentro del contexto de las luchas de bandos, existen algunos casos en los que los criados accedieron a cargos políticos, sobre todo relacionados con el regimiento conquense y optense. Este fue uno de los instrumentos empleados por la nobleza territorial para lograr el control indirecto del concejo. Los señores de Cañete patrimonializaron el cargo de guarda mayor de Cuenca durante la mayor parte del siglo XV, desde el cual pudieron favorecer la presencia de numerosos allegados y criados del linaje ${ }^{32}$.

Un criado de Juan Hurtado de Mendoza, Rodrigo de Torres, acudió a las Cortes como procurador de Cuenca en lugar de Honorato de Mendoza, incluso fue promovido a regidor por la negociación de su señor ${ }^{33}$. Numerosos criados y escuderos de los Mendoza y Acuña ocuparon distintos oficios forales: Diego Camargo, alcalde en 1420 y alguacil en 1421, y Juan de Torres, alcalde en 1430, fueron escuderos de Diego Hurtado de Mendoza; Nuño Ramírez de Montorio, caballero de la sierra en 1430 y alcalde en 1431,

\footnotetext{
${ }^{29}$ AGS, Cámara de Castilla, Personas, leg. 13.

${ }^{30}$ Cuenca, 20 julio 1413, ACC, Secretaría, Actas Capitulares, Libro II, fol. 20v y J. A. JARA FUENTE, Concejo, poder y élites. La clase dominante de Cuenca en el siglo XV, Madrid, CSIC, 2000 , nota 263 , p. 213.

${ }^{31} \mathrm{El}$ linaje actuaba como familia extensa, y la autoridad y la solidaridad estaba garantizada por el pariente mayor. La clientela era creada por un linaje, que promocionaba a personajes de segunda fila. Los bandos y parcialidades aparecían como consecuencia de los conflictos civiles y del fortalecimiento de determinados linajes dentro del ámbito urbano, M. ${ }^{\mathrm{a}}$ C. QUINTANILLA RASO, Política ciudadana y jerarquización del poder. Bandos y parcialidades en Cuenca, "En la España Medieval”, 20 (1997), pp. 219-250 y J. I. ORTEGA CERVIGÓN, Lazos clientelares y bandos nobiliarios conquenses durante el siglo XV, "Espacio, Tiempo y Forma. Serie III. Historia Medieval", 19 (2006), pp. 211-231.

${ }^{32}$ Algunos datos sistematizados sobre la naturaleza y características de este oficio concejil en el trabajo de J.I. ORTEGA CERVIGÓN, El intrusismo nobiliario en los concejos castellanos: el oficio de guarda mayor de Cuenca durante el siglo XV, en J. F. JIMÉNEZ, J. EIROA y J. ORTUÑO (eds.), Actas I Simposio de Jóvenes Medievalistas. Lorca 2002, Murcia, 2003, pp. 147-162.

${ }^{33} 20$ marzo y 12 abril 1469 , AMC, leg. 198 , exp. 3 , fols. $20 \mathrm{v}-22 \mathrm{v}$ y $28 \mathrm{v}-29$, cit. C. OLIVERA SERRANO Inventario de la documentación medieval de las Cortes de Castilla y León en el Archivo Municipal de Cuenca (1250-1500), "En la España Medieval", 20 (1997), docs. 228-233, pp. 397398 .
} 
era criado de Diego Hurtado de Mendoza; Ochoa Díaz de Montoya, alcalde en 1431 y 1451, aparecía actuando en representación de Diego Hurtado de Mendoza en 1436; Juan de Olivares, alguacil en 1471, Antón Deza, alcalde en 1476 y caballero de la sierra en 1478 y 1479, y Juan de Fitero, almotacén en 1478, eran escuderos de Juan Hurtado de Mendoza; García Álvarez de Salas, teniente de alcalde por Lope Vázquez de Acuña en 1417 y alcalde en 1420; Pedro de Salas, almotacén en 1455 y alcalde de mestas y cañadas por Pedro de Acuña en 1460; Luis de la Banda también fue alcalde de mestas por Pedro de Acuña a comienzos de la década de los sesenta; Diego de Velasco, fiel de caballero de la sierra en 1463, fue escudero de Lope Vázquez de Acuña $^{34}$. Algunos escuderos de los linajes de la nobleza territorial pertenecían al cabildo de caballeros y escuderos de Cuenca, como Pedro de la Carrera, escudero de Juan Hurtado de Mendoza y Fernando de Ortesuela, escudero de Lope Vázquez de Acuña ${ }^{35}$.

En el ámbito urbano de Huete las familias que tenían lazos clientelares con la nobleza territorial obtuvieron una notable presencia en la vida local, como Gómez Fernández Zamora, escudero de Pedro Carrillo de Huete, o Juan Daza, teniente de alcalde de las alzadas por el propio Halconero. Alfón de la Muela, cuyos lazos le asociaban a Pedro de Acuña, era escribano del concejo y alcalde entregador de la Mesta por el propio señor de Buendía. El linaje Sandoval, que ostentaba el cargo de guarda mayor de Huete, mantenía relaciones de parentela con diversas familias: Charles de Amusco figuraba como procurador sustituto de caballeros por Juan de Sandoval en 1515 y Juan de Cuenca tenía una deuda en común con Egas de Sandoval a favor de cierto vecino de La Ventosa. Además, los integrantes de la familia Parada aparecen en la documentación concejil con asiduidad desde la mitad del siglo XV, vinculados a los señores de La Ventosa; sus miembros tenían un alto nivel de formación - escribanos, bachilleres, licenciados - y desarrollaron actividades relacionados con los recursos de la tierra o el arriendo de rentas ${ }^{36}$.

Otros criados pertenecían al orden eclesiástico, normalmente como capellanes o confesores particulares ${ }^{37}$, canónigos de la Iglesia conquense o párrocos de las villas señoriales. Doña Teresa Carrillo mandó a Fernán Yáñez de Escalona, canónigo de la iglesia de Cuenca y Cartagena, criado de Lope Vázquez, "por los muchos servicios que nos fizo", el derecho, el señorío y la propiedad que tenía de las casas donde vivía en Cuenca, "en la calle que dicen de Concejo Viejo y sale a la calle que dicen de Santibáñez". Además,

\footnotetext{
${ }^{34}$ J.A. JARA FUENTE, Concejo, poder y élites..., ob. cit., notas 203, 253, 261, 263, 264 y 502 , pp. $203,211,214-215,221$ y 385.

${ }^{35}$ Ibidem, p. 363. El origen de este cabildo, no documentado, hay que ponerlo en relación con el estallido de luchas de bandos en 1417. El cabildo era un punto de apoyo monárquico en la ciudad, M. ${ }^{\mathrm{a}} \mathrm{D}$. CABAÑAS GONZÁLEZ, La caballería popular en Cuenca durante la Baja Edad Media, Madrid, 1980.

${ }^{36} \mathrm{~J}$. M. a SÁNCHEZ BENITO, El poder en una pequeña ciudad castellana: el ejemplo de Huete en el siglo XV, ob. cit., pp. 193, 203 y 210.

${ }^{37}$ Así, fray Fernando, capellán de Lope de Alarcón, señor de Valverde, recibió una mula de silla por los buenos servicios que le había realizado, Valverde, 19 enero 1472 , publ. Miguel LASSO DE LA VEGA, Marqués del Saltillo, El señorio de Valverde, Madrid, CSIIC, Instituto J. Zurita y Ayuntamiento de Cuenca, Biblioteca Conquense, t. II, 1945, doc. XXIX, p. 95.
} 
le mandó los 500 mrs. que él estaba obligado a dar por ellas como censo anual, "en tal forma que las tenga libres e forras del dicho cargo e censo para él e sus herederos". Como contraprestación espiritual, el canónigo debía rogar a Dios por el ánima de Lope Vázquez y Teresa Carrillo y de todos sus difuntos ${ }^{38}$.

\subsection{El papel de los mayordomos: la gestión de la hacienda señorial}

Los mayordomos realizaban funciones contables al controlar, administrar y gestionar las cuestiones hacendísticas, que quedaban registradas en los libros de cuentas. La administración de los bienes señoriales corría a cargo de los mayordomos, que se ocupaban de efectuar en nombre del titular del señorío las compra-ventas y los arrendamientos de tierras y propiedades, así como de recaudar las rentas y tributos; la gestión del mayordomo era completada por la tarea de cogedores, tesoreros, camareros o contadores, encargados de controlar los movimientos en dinero y en especie de la hacienda señorial. Los mayordomos se escogían entre los letrados u oficiales de los concejos del señorío ${ }^{39}$. Conocemos el nombre de alguno de los mayordomos del linaje Hurtado de Mendoza, como Juan Martínez de Molina y Pedro de Priego, mayordomos de Juan Hurtado de Mendoza ${ }^{40}$.

Los mayordomos se hacían durante ciertos años cargo de la hacienda del señor, que tomaban anualmente cuenta de todo lo que recibía y daba, de lo cual el mayordomo conservaba "cartas de pago de los fenesçimientos de cuenta" que con su señor había realizado, como Juan de Alarcón, mayordomo de Lope de Alarcón, señor de Valverde. Éste mandaba a su hijo Diego de Alarcón y a los demás herederos que,

acatando los buenos serviçios que me ha hecho, que al dicho mi mayordomo le quieran honrrar e hazelle mercedes e que no le demanden cuenta ninguna de las pasadas, saluo desde el dia que Álvaro de Tejad e yo le tomamos cuenta, la qual esta firmada de mi nonbre, e la monta que le oviere de tomar que la tome fray Fernando, mi capellan, e que le de carta de finiquito, e que aprueben e den por buenas todas las cuentas que yo le tome al dicho Johan de Alarcón, mi mayordomo ${ }^{41}$.

\footnotetext{
${ }^{38}$ Portilla, 3 agosto 1446, RAH, Salazar y Castro, D-13, fols. 5r-15r. Estas casas, heredadas de su padre Gómez Carrillo por merced que le hizo en su casamiento, tenían por aledañas las casas de Diego de Molina; de la otra parte, las casas de Lope Fernández de Caja; de la otra parte, la calle de Santibáñez y las casas de herederos de Fernán López de Calatayud.

${ }^{39} \mathrm{M} .{ }^{\mathrm{a}} \mathrm{C}$. QUINTANILLA RASO, Haciendas señoriales nobiliarias en el reino de Castilla a fines de la Edad Media, en Historia de la Hacienda Española. Epocas antigua y medieval, Madrid, 1982 , p. 797. Los mayordomos se convirtieron también en representantes locales del señor, I. BECEIRO PITA, Los estados señoriales como estructura de poder en la Castilla del siglo XV, en A. Rucquoi (coord.) Realidad e imágenes del poder. España a fines de la Edad Media, Valladolid, 1988, p. 318.

${ }^{40}$ Tragacete, 22 julio 1477, AGS, Cámara de Castilla, Pueblos, leg. 20, nº 553 y 5 diciembre 1485, RAH, Salazar y Castro, M-9, fols. 38-39v.

${ }^{41}$ Valverde, 19 enero 1472, publ. M. LASSO DE LA VEGA, El señorío de Valverde, Madrid, CSIC, Instituto J. Zurita y Ayuntamiento de Cuenca, Biblioteca Conquense, t. II, 1945, doc. XXIX, p. 95. En otra cláusula del testamento, Lope de Alarcón mandaba al mayordomo "vn sayo de buen paño por cargo que del tengo y porque ruege a Dios por mi anima", p. 96.
} 
Pedro González de Cuenca, criado de García Álvarez de Albornoz, aparece en distintos cometidos relacionados con la entrega de determinados pagos: 300 mrs. a Alfonso Martínez de Valverde; el importe de 24 reses del refitor y el préstamo de Solera del año de 1419, que había recibido de Alfonso González de Cañizares; la obligación para satisfacer a Benito Fernández, racionero de la catedral, "5 florines de oro en virtud del mantón verde, forrado en veros, propiedad de la que fuera mujer de García Álvarez de Albornoz"; o el pago a Pedro López Serrano, pitancero del cabildo catedralicio, de $100 \mathrm{mrs}$. por los oficios realizados por el ánima doña Guiomar, mujer de Garci Álvarez de Albornoz ${ }^{42}$.

Los mayordomos eran los encargados de resolver las deudas que los miembros de los linajes o de sus vasallos podían tener con personas particulares o con los concejos de Cuenca o Huete. Hay algunos testimonios de endeudamiento con determinadas personas del entorno geográfico cercano a los señoríos, como el protagonizado por Juan Hurtado de Mendoza, a quien Juan de Atienza reclamaba en 1480 la devolución de 12.500 mrs. que su padre -ya difunto- le había prestado "hace seys años poco más o menos", a lo que el noble conquense había puesto "escusas y dilaçiones" a los requerimientos de su tutor Juan de Concejo. El Consejo Real le mandó que pagara al tutor la deuda "contraída más todas las costas e dannos que sobre la rasón se le han recrecido" 43 .

También en 1480 Juan Sánchez de Miguel, vecino de Villanueva de Alcorón, aldea perteneciente al sexmo de la Sierra, solicitó una comisión para que la villa de Poyatos le pagara los 15.000 maravedís que aún le debía de los que en ella le fueron librados por Juan Hurtado ${ }^{44}$. Asimismo, el bachiller Pero Díaz, vecino de Cifuentes, solicitó en 1494 al corregidor de Cuenca una comisión para cobrar ciertas cantidades que le debían unos vecinos de Poyatos $^{45}$.

Alfonso García el Romo, vasallo y “durante gran tiempo" mayordomo de Pedro de Acuña, que había sido bien servido y su hacienda acrecentada, no había recibido salario ni quitación alguna por el desempeño de su mayordomía, y asimismo "porque él tenía gastados algunas cuantías de maravedís, pan y otras cosas, y que no tenía libramientos ni cartas de pagos suyas", el conde de Buendía ordenaba que su cuenta fuera recibida por su juramento: así, todo el pan, vino, maravedís, ganados y otras cosas que se le alcanzaran, debían cobrarse y obtener finiquito. A su vez, don Juan Alfonso de Jaén, su contador, había recibido diversas cuantías de maravedís, pan y otras cosas, y

\footnotetext{
${ }^{42}$ Cuenca, 8 abril y 24 agosto 1419,9 noviembre 1420 y 3 enero 1421, Libros de Actas Capitulares..., docs. 236, 352, 661 y 690, pp. 106, 142, 244 y 256.

${ }^{43} 25$ octubre 1480, AGS, RGS, fol. 210.

${ }^{44}$ Toledo, 12 junio 1480, AGS, RGS, fol. 181. Juan Sánchez de Miguel se quejó ante el corregidor de Cuenca, Juan Osorio, que había requerido reiteradas vẹces que le pagaran los $15.000 \mathrm{mrs}$. y no habían querido, "prouiendo a ello sus escusas e dilaçiones".

${ }^{45} 17$ noviembre 1494 , AGS, RGS, fol. 382.
} 
había hecho libranzas y dado finiquito y cartas de pago por su mandado, por lo que se procedería como en la cláusula anterior ${ }^{46}$.

Leonor de Tapia, vecina de Alcocer, mujer de Hurtado Díaz de Mendoza, difunto, tenía un "conosçimento" sobre el conde de Priego de $79.000 \mathrm{mrs}$. firmado de su abuelo y padre, por lo que aquel fue apremiado por una cédula real a pagar lo que le debía. El noble no lo quiso hacer poniendo "sus escusas yndeuidas", y como "ella es pobre e biuda, e el dicho conde persona poderosa, no podría de aver nin alcançar cunplimiento de justicia”. Este testimonio realza la indefensión que los hombres y mujeres del común sentían ante las personas de rango nobiliario, así como muestra la desconfianza ante el sistema jurídico que dirimía este tipo de conflictos. Luis de Ortega, vecino de Molina, también acusó al conde de Priego de una deuda de 12.500 mrs. por virtud de un conocimiento, ciertas cantidades que le habían de pagar las villas de Priego y Cañaveras, y el plazo había expirado en muchos días, porque él había puesto escusas y dilaciones ${ }^{47}$.

En 1491 se ordenó a Pedro Vaca, maestresala y corregidor de Cuenca y Huete, que acudiera con la recaudación de las penas pertenecientes a la cámara y fisco reales y para la guerra de los moros, del lugar de señorío de Juan Hurtado de Mendoza Poyatos — que ascendía a 100.000 mrs. - y de otras personas y concejos de las ciudades de Cuenca y Huete, al receptor de las penas pertenecientes a la cámara, Juan de Ramírez ${ }^{48}$.

En la época en que Lope Vázquez de Acuña tenía ocupada la ciudad de Huete, algunos vecinos debían pagar ciertas deudas a mercaderes gitanos, judíos y moros, "que estauan encastillados e en la conpañía de Lope Vázquez", al que habían tomado pan, vino, ganados, cantidades de mrs. y otras cosas durante la guerra, bienes que solicitó al retornar a la obediencia de la reina Isabel. Los vecinos de Huete protestaron porque se había capitulado que "quales quier mrs. e pan e otras cosas que de la fasienda y bienes" del arzobispo de Toledo, de Lope Vázquez y de las otras personas que "estauan en opinión del adversario", no se pudiesen pedir ni demandar ${ }^{49}$.

Sobre las deudas que muchos particulares tenían con él, existe el caso de unos arrendadores que, cuando Lope Vázquez estuvo en la ciudad de Huete, cobraron en su nombre determinadas rentas y se negaron posteriormente a darle cuenta de ello. El noble

tomó algunos fasedores que touieron cargo de su casa e fasienda, e los quales dis que resçibieron e cobraron por él e en su nonbre muchas cuentas de pan e rentas e vino e ganado e oro e plata e otras cosas, los quales dis

\footnotetext{
${ }^{46}$ Buendía, 25 octubre 1482, RAH, Salazar y Castro, D-13, fols. 95r-97v.

${ }^{47}$ Madrid, 22 noviembre 1494, AGS, RGS, fol. 498 y Valladolid, 23 marzo 1496, AGS, RGS, fol. 64 .

${ }^{48}$ Córdoba, 15 julio 1491, AGS, RGS, fol. 35. El corregidor de Cuenca y Huete había ordenado al concejo de Poyatos pagar $100.000 \mathrm{mrs}$. por cierta pena en que cayeron e incurrieron.

${ }^{49}$ Sevilla, 20 agosto 1477, AGS, RGS, fol. 438. La reina dio por "libres e quitos" a los vecinos de Huete, por cuanto habían sido robados y no debían pagar más de una vez.
} 
que por su absençia se fan alçado e sobreseydo de le dar cuenta con pago de lo que asy resçibieron e recabdaron ${ }^{50}$.

También reclamó a la ciudad de Huete determinadas rentas de las escribanías que le pertenecían y dejó de percibir durante varios años, a razón de 8.000 mrs. anuales. Este privilegio había sido obtenido por Pedro de Acuña en $1430^{51}$. La ciudad de Huete pidió en 1479 la revocación de contratos de censos abusivos impuestos "por fuerça e por myedo y temor del dicho Lope Vásques", ya que habían sido "engañados e defraudados en ello". El noble pretendía cobrar una renta de dos cahíces por tierras que solo producían esa cantidad:

\begin{abstract}
Al tienpo que Lope Vásques de Acuña tenía ocupada la dicha çibdad e su tierra fiso faser a çiertos conçejos de la dicha tierra e muchas personas syngulares della, forçosamente, por el grand miedo e temor que le tenían, muchos contratos de çensos y rentas de su tierras y heredamientos que en la tierra de la dicha çibdad tenya [...], que en lo que meresçía dos cafíses de pan lo fasía arrendar e ençensar por dies cafíses ${ }^{52}$.
\end{abstract}

Por último, también hallamos a los mayordomos en los numerosos pleitos que trataban las villas del entorno serrano con la ciudad de Cuenca por la delimitación de términos, como Juan Martínez de Molina, mayordomo de Juan Hurtado de Mendoza ${ }^{53}$. También había mayorales, que tenían el cometido de recaudar rentas del señor ${ }^{54}$.

\title{
3. EPISODIOS DE VIOLENCIA URBANA Y RURAL
}

La Baja Edad Media castellana fue un período de especial virulencia política y social, tanto el plano urbano de las luchas de bandos como en el de las relaciones entre señores y campesinos. En el caso de la nobleza conquense, existen testimonios en los que las fechorías también eran cometidas por los criados de algunos señores, especialmente para saldar cuentas fuera de la justicia ordinaria. Celdrán, criado de Pedro de Barrientos, atacó e hirió a Juan de Losillo, vecino de Cuenca, por el "odio e enemistad" que con él tenía el regidor conquense. Algunos episodios se enmarcan en la violencia urbana y en las luchas de bandos, como el caso de Juan de Losillo, vecino de Cuenca,

\footnotetext{
${ }^{50}$ Toledo, 11 febrero 1480, AGS, RGS, fol. 120. Lope Vázquez se quejó de que el prior de Uclés, a quien se había encomendado la labor de "conoscer los dichos negocios", había dejado de usar tal comisión por mandado de los reyes, que advocaron los pleitos al doctor Alfón Díaz de Montalbo, oidor de la Audiencia, çuya jurisdicción no podía actuar "más de ocho leguas allrededor de la dicha çibdad de Huete", Toledo, 11 febrero 1480, AGS, RGS, fol. 213.

${ }^{51}$ Lope Vázquez reclamaba los derechos de los escribanos de Huete, ya que el concejo había dejado de pagarle "de tres años a esta parte". El privilegio fue concedido por Enrique IV y confirmado por los reyes Isabel y Fernando, Toledo, 11 febrero 1480, AGS, RGS, fol. 184

${ }^{52}$ Toledo, 18 noviembre 1479 , AGS, RGS, fol. 30.

${ }^{53}$ Tragacete, 22 julio 1477 , AMC, leg. 120 , exp. 5 , fol. 2 r.

${ }^{54} \mathrm{La}$ documentación menciona al mayoral de Lope Vázquez, AMC, leg. 185, exp. 3, fol. 22r.
} 
que por odio e enemistad que con él dis que tyene Pedro de Barrientos, regidor e veçino de Cuenca, syn cavsa ni culpa suya, se teme e reçela que el dicho don Pedro e sus parientes e amigos, o criados o otras personas que por él han de faser, le ferirán, o matarán, o lisyarán, o prenderán, o le tomarán o mandarán tomar sus bienes, ynjustamente e non devidamente, en lo qual, sy asy pasase dis que él resçebiría grand agravyo e daño. E nos suplicó e pidió por merçed çerca dello, con remedio de justiçia, le mandásemos por ella mandándole dar nuestras cartas de seguro e anparo para que le no fuese, nin sea fecho ningún mal, nin daño nin otro desaguisado alguno en su persona nin en los dichos sus bienes ${ }^{55}$.

Los temores de Juan de Losillo - que años después figura en la documentación como criado de Diego Hurtado ${ }^{56}$-, se vieron confirmados, según consta en otro documento fechado el mismo día 1 de mayo de 1494 y dirigido al corregidor o juez de residencia de Cuenca:

En vn día del mes de abril que agora pasó deste presente año de la data desta nuestra carta, diz que don Pedro de Barrientos, veçino e regidor de la dicha çibdad, syn faser nin desir por qué mal nin daño devyese reçebir, diz que le dixo muchas palabras de amenazas, e por quel diz que dixo “;biba el Rey e la reyna, que no he miedo a nadie!”, diz que estando çerca del monasterio de Sant Françisco de la dicha çibdad, diz que salió a él Çeldrán, criado del dicho don Pedro, por su mandado e con su fauor, pospuestos el temor de Dios e de nuestra justiçia, armado de tales armas e con vna espada sacada en la mano para le ferir e matar. E diz que lo syguió fasta lo ençerrar en el monasterio e diz que entró tras él e le dio dos cuchilladas en un braço de que le cortó el cuero e la carne, e le salió mucha sangre, de las quales dichas feridas diz que él ha allegado y está a punto de muerte. E diz que como quiera que lo suso dicho vino a notiçia de vos, el dicho corregidor, e vos fue denunçiado, diz que por ser el dicho don pedro onbre poderoso e vuestro amigo, e mui enparentado en la dicha çibdad, diz que non le ha seydo fecho conplimiento de justiçia ${ }^{57}$.

Durante el reinado de Juan II, en el contexto de enfrentamiento entre los linajes Hurtado de Mendoza y Vázquez de Acuña por el poder concejil de Cuenca, hallamos otro episodio de violencia urbana. El concejo había informado al rey de que Rodrigo de Mendoza, acompañado de ciertos beneficiados del cabildo, fue de noche "con grant armada e conbatyeron la casa de Alonso Paes de Ecija, vuestro alguacil". Iban armados con lanzas y piedras, y habrían matado al alguacil y a los que con él estaban si éstos no se hubieran defendido. Los alcaldes de Cuenca hicieron una pesquisa sobre el asunto e informaron al monarca de lo acaecido. Tras estos incidentes, Rodrigo

\footnotetext{
${ }^{55}$ Medina del Campo, 1 mayo 1494, AGS, RGS, fol. 315. Don Fernando y doña Isabel se dirigen en este documento "a los alcaldes de la nuestra casa, e corte e chançellería, e a todos los corregidores e asystentes, alcaldes e otras justiçias, jueses quales quier, asy de la çibdad de Cuenca, como de todas las otras çibdades, villas e lugares de los nuestros Reynos e señoríos".

${ }^{56}$ Martín de Mariana y Juan Losillo, criados de Diego Hurtado, participaron en un pleito sostenido entre vasallos de éste y la ciudad de Cuenca, Cuenca, 26 y 30 junio 1503, AGS, Cámara de Castilla, Pueblos, leg. 15, no 495-496.

${ }^{57}$ Medina del Campo, 1 mayo 1494, AGS, RGS, fol. 318.
} 
de Mendoza se había refugiado en la ermita de San Miguel de Ortaleza, situada a una legua de la ciudad,

e los omes que con el yvan sallian a robar por los montes demandando cabritos a los omes que guardavan los ganados, e tomando a los que yvan por lenna las capas e los punnales... que levavan en las bolsas, disiendo que non podian allí paçer nin cortar lenna e que era defendido, lo qual los dichos montes nunca fueron guardados nin defendidos, antes ser fue e es tierra comun desta yibdat para pager e cortar.

Rodrigo de Mendoza regresó a Cuenca y se refugió en su casa con los suyos, y al día siguiente se refugiaron todos en los palacios episcopales, por lo que no pudieron prenderles. Más tarde, un día salieron de los palacios y algunos de ellos pelearon con tres hombres que iban con Vasco, hijo de Lope Vázquez de Acuña, para llevarle a la escuela, uniéndose pronto a la pelea muchos hombres del provisor de la diócesis, Pedro Arias Bahamonde, así como del propio Rodrigo de Mendoza, de Ruy Bernal, arcediano de Alarcón, y de otros beneficiados de la catedral, y también otros hombres del bando de Lope Vázquez de Acuña, resultando heridas varias personas y armándose gran bullicio en la ciudad ${ }^{58}$.

La documentación refleja en ocasiones el temor y el recelo que les producían los nobles y sus comitivas de criados armados en el ámbito rural. Juan Romo y Alonso Romo, su primo, vecinos de La Puerta, e Miguel Fernández, vecino de Mantiel, "en nombre de los onbres e mugeres, veçinos e moradores de La Puerta, Montiel, Cerezeda y Peralveche", términos usurpados a la jurisdicción de la ciudad de Cuenca por el noble Lope Vázquez de Acuña, protestaron ante el Consejo Real que "ellos se temen e reçelan de Lope Vásques de Acuña e Lope de Acuña e de sus omes e criados" e de otras personas que con odio e malquerencia que los quemen e los feryrán o matarán o lysiarán o farán otro mal o daño o desaguisado alguno, por lo que suplicaron remedio de justicia" ${ }^{59}$.

\section{LAS MANDAS TESTAMENTARIAS: LA VINCULACIÓN AFECTIVA HACIA LOS CRIADOS}

La documentación testamentaria es una fuente histórica fundamental para bucear en la llamada historia de la vida privada y la historia de las mentalidades que tanto éxito historiográfico tuvieron en la segunda mitad del siglo pasado. La vinculación afectiva de los señores hacia sus criados y servidores quedaba patente en los pagos que recibían los criados en los testamentos, en los que quedaban saldadas anteriores deudas.

\footnotetext{
${ }^{58}$ J. DÍAZ IBÁÑEZ, Las relaciones Iglesia-Nobleza en el obispado de Cuenca durante la Edad Media, "En la España Medieval", 20 (1997), p. 287. La ciudad de Cuenca fue puesta en entredicho por el provisor, privándose a todos los ciudadanos de recibir los sacramentos.

${ }^{59}$ Córdoba, 26 abril 1485, AGS, RGS, fol. 269.
} 
En el caso concreto de la nobleza territorial conquense son numerosos los ejemplos de estas disposiciones. Juan de Sandoval le entregaba a Gonzalo de Comega $1.500 \mathrm{mrs}$. por el servicio que le había hecho; a Fernandillo, hijo de Fernando Gómez Castellano, 1.000 mrs.; a Lope y a Juanillo 200 mrs. cada $u n o^{60}$. Lope de Alarcón, señor de Valverde, mandó en su carta testamentaria de 1472 que pagaran a su criado Juan de Talayuelas $4.000 \mathrm{mrs}$. y a su mujer Isabel 4.000 mrs. para su casamiento, a su criado Perote 2.000 mrs. "y que lo vistan", y a los mozos que tenía a soldada, que hicieran cuenta con ellos y les pagaran lo que se hallare les debía. En el testamento de su hijo Pedro Ruiz de Alarcón se ordenaba pagar a Juan de Talayuelas y a Isabel su mujer, "todo lo que mi padre les dexó mandado, aunque se les descontaba lo que yo les tengo pagado dello, lo qual sabe Juan de Alarcón, mi mayordomo, o juren ellos que tienen reçebido e les paguen todo lo que les deuiere de sus soldadas". De la misma forma, a Perote, lo que Lope de Alarcón dejó mandado, "e le acaben de dar las armas que fueren neçesarias para vn escudero, pues tiene caballo" 61 .

Pedro de Acuña ordenaba que sus criados fueran pagados y satisfechos de la cuantía que dejaba declarado, por lo que mandaba una relación firmada en poder de su padre y confesor fray Miguel de Busto, guardián del monasterio de San Juan de los Reyes de Toledo. A su vez, mandaba a su criado Alfonso Ortiz de Cazorla la parte de las casas en las que él vivía en Dueñas que salían al Mercado, y una tierra que le dio colindante con el prado de la Vega Rodeno y con la mata y guindales de Juan Caballero, todo ello en descuento de lo que se hallara que le debía del ganado que él tomó de Juan de Tovar $^{62}$.

En el testamento de Lope Vázquez de Acuña y Teresa Carrillo de Albornoz se exponía en una cláusula que "los criados no tomen jerga ni llanto, ni hagan más que rogar a Dios por nuestras ánimas". A determinados criados, "por cargo que tenemos de él", les concedían determinados emolumentos: a Juan de Velasco, 3.000 mrs.; a Rodrigo Álvarez Gallego, 1.000 mrs.; a Martín Rodríguez, 1.000 mrs.; a Juan Fraile y a su mujer, 1.000 mrs. Los propios señores expresaban que si cualquiera de ellos no satisficieran en sus vidas a todos sus otros criados y criadas, que los ejecutores de su testamento lo hicieran "según los tienpos que nos hubieran servido"63.

Algunos señores mostraban su generosidad otorgando ayudas económicas para que sus criados pudieran casarse, y se preocuparon en que muchos de ellos adquirieran armas y caballo para convertirse en escuderos. Pedro Ruiz de Alarcón, señor de Valverde, dio a Pedro de Montoya 10.000 mrs. para su casamiento, "pues yo le encaualgue e le di las armas que le fueron necesarias"; a Martín de Merino, 5.000 mrs.; a Artiaga "que le den

\footnotetext{
${ }^{60}$ Huete, 9 enero 1470, AHN, Consejos, leg. 37.789, $\mathrm{n}^{\mathrm{0}}$ 5.692, fols. 6-8.

${ }^{61}$ Valverde, 19 enero 1472 , publ. M. LASSO DE LA VEGA, El señorío de Valverde, ob. cit., docs. XXIX y XXXVIII, pp. 95 y 128.

${ }^{62}$ Buendía, 25 octubre 1482, RAH, Salazar y Castro, D-13, fols. 95r-97v.

${ }^{63}$ Portilla, 3 agosto 1446, RAH, Salazar y Castro, D-13, fol. 5r.
} 
vna mula buena o cauallo qual el mas quisiere e armas suficientes para el", y 5.000 mrs. para su casamiento; a Roa, que le había servido "muy bien e mas que otro ninguno en tan poco tienpo de los que yo he tenido", que le pagaran todo lo que perdió cuando el marqués de Villena tomó el lugar de Santa María del Campo; a Sepúlveda, su paje, que le dieran caballo y armas igual que otros criados, "e le den de vestir e le pongan con vn señor"; a Villanueva, que fue mozo de espuelas, que le den $10.000 \mathrm{mrs}$., "porque yo no he conplido con el e me siruio bien e le despedi con enojo"; a Mayor, que le den $10.000 \mathrm{mrs}$. "que avia de aver Andres, mi criado, e por el delito que cometio e fiso con la dicha Mayor e después no se casó con ella, los mando dar a la dicha Mayor" ${ }^{64}$. Los condes de Buendía destinaron ciertas cantidades para el casamiento de sus criados: a Isabel, 3.000 mrs.; a María Mejía, 10.000 mrs.; a Teresa, 12.000 mrs.; a Isabel de Podata, 10.000 mrs.; a Juana Ruiz -que vivía en unas casas que los señores tenían en la plaza de Buendía-, 2.000 mrs. ${ }^{65}$.

En otras ocasiones se delegaba esta función en otra persona de la casa, habitualmente las esposas. Pedro Ruiz de Alarcón se excusaba

porque yo non terne casi memoria de las moças e criadas que en mi casa se an criado e de otras personas a algunas, asi como doña Maria, mi muger, porque ella lo ha visto mas contino, remitome a ella e a mis testamentarios que en aquello descarguen mi conciencia ${ }^{66}$.

Gonzalo Suárez, hijo de Melen Suárez, alcaide de Alejo de Sandoval, señor de La Ventosa, para satisfacer su servicio, ordenó que se le entregaran para su casamiento los maravedís que rentaran los frutos de la prestamera de Horcajada del año 1500. Su pariente y criado Gutierre Patiño, al tiempo de su matrimonio, no había recibido nada, por lo que ahora su hijo Pedro Patiño recibiría un potro o caballo "para que se encabalgue cuando haia edad para ello". Aguilar recibió un potro "que tengo en mis yeguas que fase agora dos años", y encomendaba a Gutierre de Sandoval a recibirlos como suyos ${ }^{67}$. Éste solicitaba en una disposición testamentaria a su esposa doña Elvira que satisfaciera a los mozos que le habían servido lo que tenía concertado con ella, que lo sabe, de entre su bienes. Debía pagar una cuenta a Alejo Díaz, dar a Arnedo 15.000 mrs. cuando se hubiera de casar - la mitad de esa cantidad en ropas de paño y seda de su persona-, dar a Batista un potro - el mejor que en mis yeguas se hallare- y satisfacerle el tiempo que le había servido, así como a Monterroso ${ }^{68}$.

\footnotetext{
${ }^{64}$ Así figura en su testamento, Jaén, 30 diciembre 1485, publ. M. LASSO DE LA VEGA, El señorio de Valverde, ob.cit. doc. XXXViIII, p. 128.

${ }^{65}$ Portilla, 3 agosto 1446, RAH, Salazar y Castro, D-13, fol. 5r.

${ }^{66}$ Así figura en su testamento, Jaén, 30 diciembre 1485, publ. M. LASSO DE LA VEGA, El señorio de Valverde, ob.cit., doc. XXXVIII, p. 128.

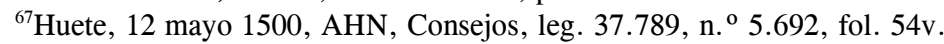

${ }^{68}$ La Ventosa, 4 septiembre 1506, AHN, Nobleza, Priego, C. 2, D. 17.
} 
Juan Hurtado de Mendoza exponía que las cosas que se hubieran de dar a sus criados que "de contino" le servían en satisfacción de sus servicios, quedara a determinación de su mujer doña Elvira, "porque çerca desto yo hablé con ella y sabe mi voluntad"

Muchos criados continuaban al servicio de alguno de los hijos al fallecer ambos cónyuges. Doña María Carrillo, viuda de Martín Ruiz de Alarcón, señor de Valverde, señalaba en su testamento "que satisfechas mis criadas et criados, de aquellos quien yo tengo cargo, que los aya e herede la dicha Doña María Carrillo, mi fija, por seruicios muchos e buenos que me ha fecho"70. Juan de Sandoval ordenó a su hijo Gutierre que tuviera en cargo a su criado Fernando, hijo de Fernando Martínez Crespo, y le hubiera encomendado para que le hiciera bien y lo tuviera consigo ${ }^{71}$.

Por último, nos referiremos a la casi inexistencia de esclavos entre la nobleza conquense bajomedieval ${ }^{72}$. De hecho, solo conocemos el caso de unos esclavos del conde de Buendía que recibieron la manumisión a su muerte. Andrés Garrote, Alfonso de Herrera y María de Herrera, y sus hijos e hijas, y Bricar, habían sido esclavos de Pedro de Acuña, y la voluntad de éste era que en su vida le sirviesen como le habían servido, y que después de sus días fueran "libres e quitos para siempre jamás", y no les fuera impuesto impedimento ni embarazo ninguno ${ }^{73}$.

\section{CONCLUSIONES}

En definitiva, los criados realizaban distintas tareas domésticas, administrativas, financieras y militares. Debían mostrarse fieles y hábiles en

\footnotetext{
${ }^{69} \mathrm{Cuenca}_{, 3}$ "dentro de las casas donde biue el dicho señor Juan Furtado que son en la calle de la Pellejería", 18 enero 1505 , ACC, Institucional, $1 / 15$, fols. 1r-25r.

${ }^{70}$ Valverde, 8 diciembre 1451, publ. M. LASSO DE LA VEGA, El señorío de Valverde, ob. cit., doc. XXVI, p. 80. Otra cláusula testamentaria ordenaba a sus hijos Lope de Alarcón y Juan Carrillo que todas las criadas de las que tenía cargo fueran pagadas de sus bienes, "segund que a ellos bien visto fuere et será".

${ }^{71}$ Huete, 9 enero 1470, AHN, Consejos, leg. 37.789, $\mathrm{n}^{0}$ 5.692, fols. 6-8.

${ }^{72}$ Sobre el tema de la esclavitud en la península Ibérica, especialmente en el reino de Castilla, durante la Edad Media ver los trabajos de A. FRANCO SILVA, La esclavitud en Castilla durante la Baja Edad Media: aproximación metodológica y estado de la cuestión, "Historia. Instituciones. Documentos", 6 (1979), pp. 113-127 y La esclavitud en Sevilla a fines de la Edad Media (14701525). Sevilla , 1979. Éste mismo autor realizó un resumen bibliográfico años después, La esclavitud en la Peninsula Ibérica a fines del Medievo. Estado de la cuestión y orientaciones bibliográficas, "Medievalismo", 5 (1995), pp. 201-209. Para la época tardomedieval existen las aportaciones de V. GARCÍA PASTOR, La esclavitud en Castilla durante el reinado de los Reyes Católicos, en Actas I Congreso de Historia de Castilla-La Mancha, Toledo, 1988, t. VII, pp. 512 y de A. J. FURIÓ DIEGO, Mercancías humanas: el nuevo auge de la esclavitud a finat de la Edad Media, en M. Chust Calero (coord.), De la cuestión señorial a la cuestión social. Homenaje al profesor Enric Sebastià, Valencia, Universitat de Valencia, 2002, pp. 23-38.

En la Castilla centro-oriental conocemos el caso de los condes de Cifuentes en el siglo XV: disponían de esclavos procedentes del reino de Granada que participaban en el servicio doméstico. Asi, en 1462 el rey Enrique IV regaló a Alfonso de Silva a Elvira y Cira, y Juan de Silva II, en su testamento, dijo que se manumitiese a Alonso. Por los nombres empleados, parece ser que fueron bautizados, M. B. RIESCO DE ITURRI, Propiedades y fortuna de los condes de Cifuentes. la constitución de su patrimonio a lo largo del siglo XV, "En la España Medieval", 15 (1992), p. 153 .

${ }^{73}$ Buendía, 25 octubre 1482, RAH, Salazar y Castro, D-13, fols. 95r-97v.
} 
el manejo del dinero, en los asuntos políticos y en las acciones bélicas. La Dra. Sánchez Prieto, en su análisis de la Casa de los duques del Infantado, expone que el mantenimiento de un gran número de criados y servidores no respondía solamente a razones funcionales dentro del servicio de la casa y la administración de los estados señoriales, sino que era también una forma de demostrar el prestigio social al mostrar un lúcido sequito de gentes armadas, caballeros y escuderos. Los criados que aparecen como testigos en diversas acciones jurídicas de sus señores (compraventas, capitulaciones matrimoniales, compromisos políticos) eran los de mayor categoría dentro de la casa y, por consiguiente, los de condición noble. Por último, subraya la confianza que había en el criado, ya que muchas veces ponían en él sus compromisos políticos $^{74}$.

En especial adquiría gran relieve la labor de los criados escuderos, que eran elemento esencial en los grupos para y plurifamiliares que se encadenaron en las estructuras sociales del siglo $\mathrm{XV}^{75}$. En palabras de la profesora Gerbet, "los criados y sus señores formaban un grupo tan unido que contribuía a la cohesión social, favorecía la ascensión personal, incluso hasta la figura del rey. Era un hecho muy estructural. Esto era así porque nunca se le prohibió a los nobles tenerlo. El clientelismo era demasiado consustancial a su modo de vida y de acción"76. Visto desde este ángulo, queda remarcada la necesidad de los linajes del concurso o servicio de muchos personajes de su entorno clientelar: los criados se encargaban del servicio doméstico y los allegados se ocupaban del apoyo político-militar.

Fecha de recepción del artículo: mayo 2009.

Fecha de aceptación y versión final: julio 2009.

${ }^{74}$ A.B. SÁNCHEz PRIETO, La Casa de Mendoza hasta el tercer Duque del Infantado (13501531). El ejercicio y alcance del poder señorial en la Castilla bajomedieval, Madrid, Palafox \& Pezuela, 2001, pp. 252-253.

${ }^{75}$ M. ${ }^{\text {a }}$ C. CARLÉ, ob. cit., pp. 120-121.

${ }^{76}$ M.-C. GERBET, Nobles et clients dans le Royaume de Castille: criados et allegados en Estrémadure dans des années 1500, ob. cit., p. 342. 